\title{
Fusión de ecocardiografía 2D/3D-fluoroscopia: nueva herramienta en el intervencionismo cardiaco
}

\author{
José Julián Carvajal-Rivera ${ }^{\mathrm{a}, \mathrm{b}, *}$, Miguel Ángel García Fernández ${ }^{\mathrm{b}, \mathrm{c}}$, \\ Johanna Carolina López-Quintero ${ }^{\mathrm{b}, \mathrm{d}}$, Leopoldo Pérez-de Isla ${ }^{\mathrm{a}, \mathrm{b}, \mathrm{c}}$ \\ y Gustavo Restrepo Molina ${ }^{e, f, g}$
}

\author{
a Hospital Clínico San Carlos, Madrid, España \\ b Universidad Complutense de Madrid, Madrid, España \\ c Sociedad Española de Cardiología, Sección de Imagen Cardiaca, Madrid, España \\ ' Universidad El Bosque, Bogotá, Colombia \\ e Laboratorio de ecocardiografía y métodos diagnósticos, Clínica Medellín, Medellín, Colombia \\ f Ecocardiografía, Facultad de Medicina, Universidad CES, Medellín, Colombia \\ s Sociedad Interamericana de Cardiología (SIAC), Ciudad de México, México
}

Recibido el 3 de febrero de 2017; aceptado el 5 de mayo de 2017

Disponible en Internet el 16 de octubre de 2017

\section{PALABRAS CLAVE \\ Imágenes de fusión; \\ Fluoroscopia; \\ Ecocardiograma \\ transesofágico; \\ Enfermedades \\ estructurales del \\ corazón; \\ Guía intervencionista}

\begin{abstract}
Resumen La evolución en el intervencionismo estructural percutáneo ha generado un desarrollo paralelo en las técnicas de imagen avanzada. Teniendo en cuenta que este tipo de procedimientos requiere un entendimiento total de la anatomía cardiaca y con el fin de garantizar los mejores resultados y seguridad para el paciente durante procedimientos complejos, se desarrolló un software capaz de fusionar la fluoroscopia y la ecocardiografía 3D en una sola imagen. La tecnología del Echonavigator ${ }^{\oplus}$ integra dos técnicas de imágenes dinámicas de un corazón en movimiento; el adecuado co-registro y visualización de fluoroscopia y ecocardiografía transesofágica 2D/3D es la clave en la obtención de resultados óptimos. La fusión de dos imágenes dinámicas en tiempo real es una herramienta factible y segura en los procedimientos de intervencionismo estructural del corazón; los estudios iniciales han logrado disminuir el tiempo de realización de los procedimientos y las dosis de radiación al paciente. El futuro es prometedor y su progresiva expansión de uso teniendo en cuenta su reciente aparición, aportará más datos en el crecimiento de esta tecnología.

(c) 2017 Sociedad Colombiana de Cardiología y Cirugía Cardiovascular. Publicado por Elsevier España, S.L.U. Este es un artículo Open Access bajo la licencia CC BY-NC-ND (http:// creativecommons.org/licenses/by-nc-nd/4.0/).
\end{abstract}

\footnotetext{
* Autor para correspondencia.

Correo electrónico: joscar83@gmail.com (J.J. Carvajal-Rivera).
} 


\section{KEYWORDS}

Fusion imaging;

Fluoroscopy;

Transoesophageal

echocardiogram;

Structural heart

diseases;

Interventionist

guidelines

\section{Fusion of 2D and 3D echocardiography with fluoroscopy: a new tool in cardiac interventionism}

\begin{abstract}
The evolution of percutaneous structural interventionism has led to the simultaneous development of advanced imaging techniques. Taking into account that these types of procedures require a full understanding of cardiac anatomy, and with the aim of ensuring the best results and patient safety during complex procedures, a software program was developed that was capable of fusing and 3D-echocardiography into a single image. The Echonavigator ${ }^{\circledast}$ technology combines two dynamic imaging techniques of a heart in movement. The appropriate co-recording and visualising of fluoroscopy and 2D/3D transoesophageal echocardiography is essential for obtaining optimal results. The fusion of two images in real-time is a feasible and safe tool in structural heart interventionist procedures. Initial studies have managed to decrease the time of performing the procedures, as well as the dose of radiation to the patient. The future is promising, and its gradual expansion of use, taking into account its recent appearance, will provide more data on the growth of this technology.

(C) 2017 Sociedad Colombiana de Cardiología y Cirugía Cardiovascular. Published by Elsevier España, S.L.U. This is an open access article under the CC BY-NC-ND license (http:// creativecommons.org/licenses/by-nc-nd/4.0/).
\end{abstract}

\section{Introducción}

En la última década, el campo del intervencionismo estructural ha venido en crecimiento rápido y continuo ${ }^{1}$. Se han introducido numerosas terapias menos invasivas para el tratamiento de enfermedades estructurales del corazón, las cuales han probado en pacientes de alto riesgo quirúrgico ser iguales o más efectivas gracias a la disminución del riesgo perioperatorio ${ }^{2-5}$.

La evolución en el intervencionismo estructural percutáneo ha generado un desarrollo paralelo en las técnicas de imagen avanzada teniendo en cuenta que este tipo de procedimientos requiere un entendimiento total de la anatomía cardiaca con el fin de garantizar los mejores resultados ${ }^{6}$. El rol de la imagen durante procedimientos estructurales percutáneos se puede dividir en tres componentes:

\section{Selección del paciente y planificación pre-} procedimiento.

2. Guía de imagen intraprocedimiento.

3. Evaluación de resultados y seguimiento a largo plazo.

Esta revisión se enfocará en el segundo punto. De manera rutinaria, la fluoroscopia se ha utilizado como guía en tiempo real para los procedimientos de intervención percutánea estructural complementado por ecocardiografía transesofágica $3 \mathrm{D}$ en tiempo real $^{7}$. Sin embargo, las técnicas por sí mismas tienen limitaciones. En el caso de la fluoroscopia, provee información importante como la visualización de estructuras óseas, cables y dispositivos y también mayor campo de visión, pero con una limitación clara en la definición de tejidos blandos y en la visualización de cavidades cardiacas y tejidos adyacentes. Por otro lado, la ecocardiografía tiene un menor campo de visión, con una menor visualización de dispositivos y catéteres pero da una excelente caracterización de tejidos y adicionalmente ofrece información fisiológica durante todo el procedimiento en tiempo real. No obstante, las dos técnicas generalmente se utilizan con diferentes orientaciones o finalidades, lo que añade un grado de dificultad mayor en la interpretación rápida de las imágenes ${ }^{8}$.

\section{Imágenes de fusión}

Las intervenciones estructurales poseen herramientas diseñadas para ser seguras y ofrecer una alta precisión dada la complejidad del procedimiento. Esto se traduce en un reto ya que implica la visualización exacta durante todo el procedimiento de los catéteres en movimiento y el material implantado con un corazón latiente. La identificación de las estructuras en tres dimensiones en múltiples modalidades de imagen y la comunicación efectiva, son piezas fundamentales en el éxito de las intervenciones.

Para facilitar esta tarea, las imágenes de fusión aparecen como una herramienta complementaria en la cual dos o más técnicas se complementan en una sola imagen con el fin de orientar y disminuir tiempo de intervención y complicaciones.

Previamente ya existían imágenes de fusión estáticas como la perfusion miocárdica con tomografía coronaria9, SPECT-ecocardiografía, $\mathrm{RMN}-\mathrm{CT}^{10}$, PET-CT ${ }^{11}$, etc. Sin embargo, en estos estudios de fusión se utilizan imágenes estáticas y no son posibles en un corazón latiendo en intervenciones en tiempo real.

Para procedimientos estructurales cardiacos, más recientemente se desarrolló el uso de imagen de fusión entre tomografía computarizada y fluoroscopia en la cual se utiliza una imagen estática y una dinámica. Esta combinación ofrece una información anatómica adecuada pero no provee imagen en tiempo real y está limitada por el movimiento traslacional del corazón debido a los movimientos respiratorios o cualquier movimiento que el paciente pueda realizar durante el mismo ${ }^{12}$ (fig. 1).

En respuesta a las necesidades de buenos resultados y seguridad para el paciente durante la realización de procedimientos complejos, se desarrolló un software capaz de 


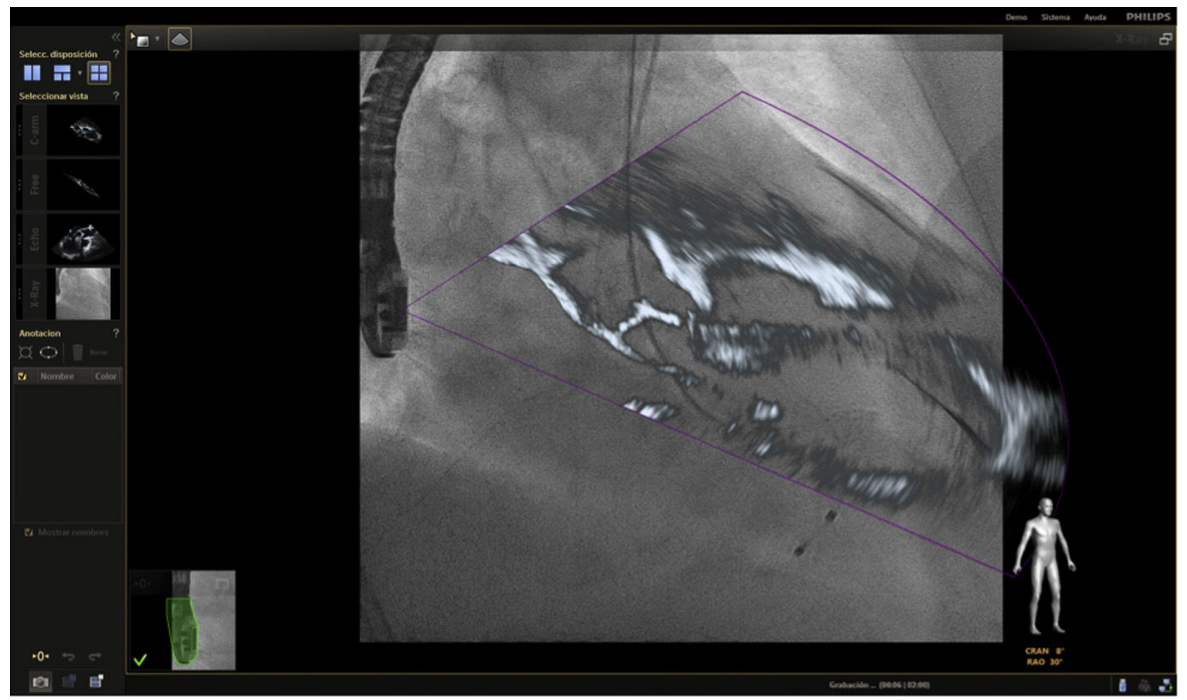

Figura 1 Imagen de fusión eco 3D/fluoroscopia. Se observa paso de la guía a través de la válvula aórtica, alojándose en el ventrículo izquierdo durante procedimiento de TAVI.

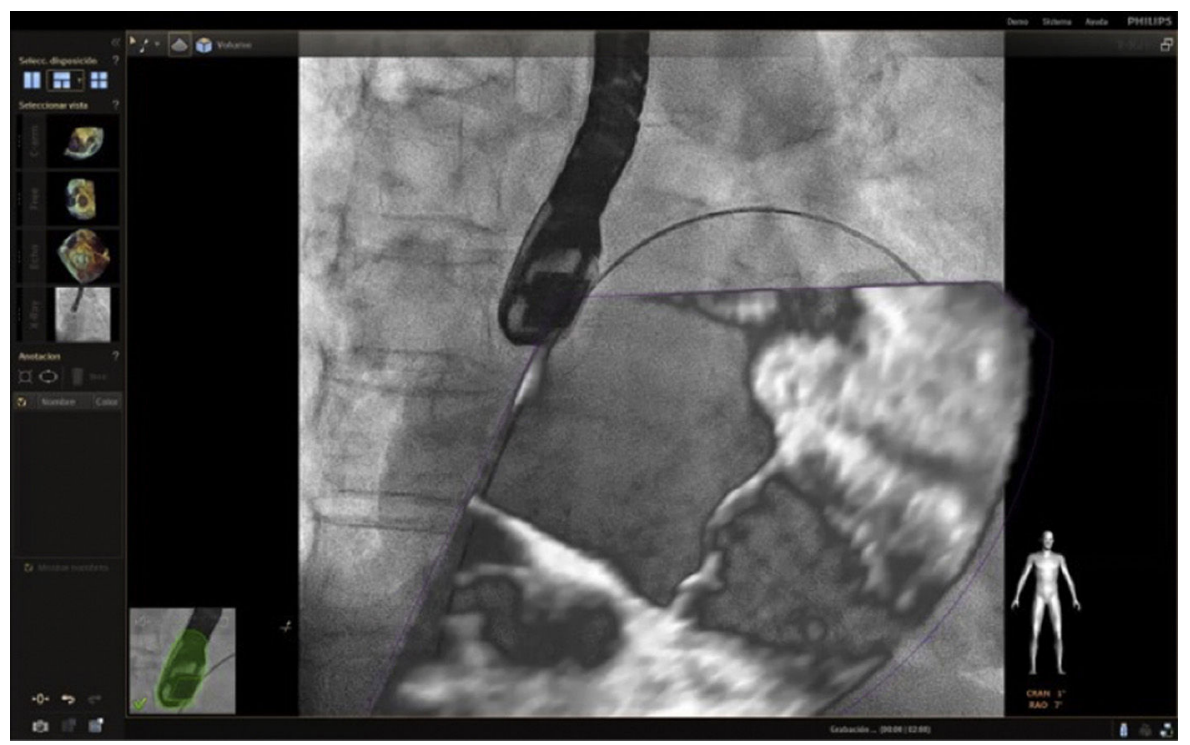

Figura 2 Imagen de fusión en ecocardiograma transesofágico 3D cuatro cámaras; se observa guía que pasa a través de septo interauricular durante colocación de Mitraclip.

fusionar la fluoroscopia y la ecocardiografía transesofágica $2 D / 3 D^{13}$ en una sola imagen (figs. 2 y 3 ). Viene utilizándose cada vez con más frecuencia, con múltiples reportes en la literatura, pues ha mostrado sus buenos resultados de eficacia y especialmente de seguridad, dando la posibilidad de su implementación en la rutina diaria.

En esta revisión se dan las pautas de su aplicación actual, así como las utilidades en cada una de las técnicas de intervencionismo empleadas, sus ventajas y limitaciones.

\section{Fusión ecocardiografía 3D/fluoroscopia}

\section{Técnica}

La tecnología del Echonavigator ${ }^{\circledR}$ integra dos técnicas de imágenes dinámicas de un corazón en movimiento. $\mathrm{El}$ co-registro adecuado y la visualización de fluoroscopia y ecocardiografía transesofágica $2 \mathrm{D} / 3 \mathrm{D}$ es la clave en la obtención de resultados óptimos. Esta sincronización se obtiene mediante un algoritmo de calibración entre la sonda transesofágica y el fluoroscopio ${ }^{14}$, gracias a la que automáticamente el sistema identifica la sonda y genera una imagen sobrepuesta a la previa de fluoroscopio.

Una vez se da esta fusión, el sistema genera una imagen compuesta que sigue la rotación del brazo del fluoroscopio a discreción del cardiólogo intervencionista. La pantalla dedicada al intervencionista ofrece la posibilidad de cuatro imágenes en simultánea con diferentes funciones. En la primera, las capturas obtenidas por la ecocardiografía transesofágica 2D/3D están a cargo exclusivamente del ecocardiografista; en la segunda la visión del fluoroscopio depende de la angulación del gantry (en esta imagen se debe 


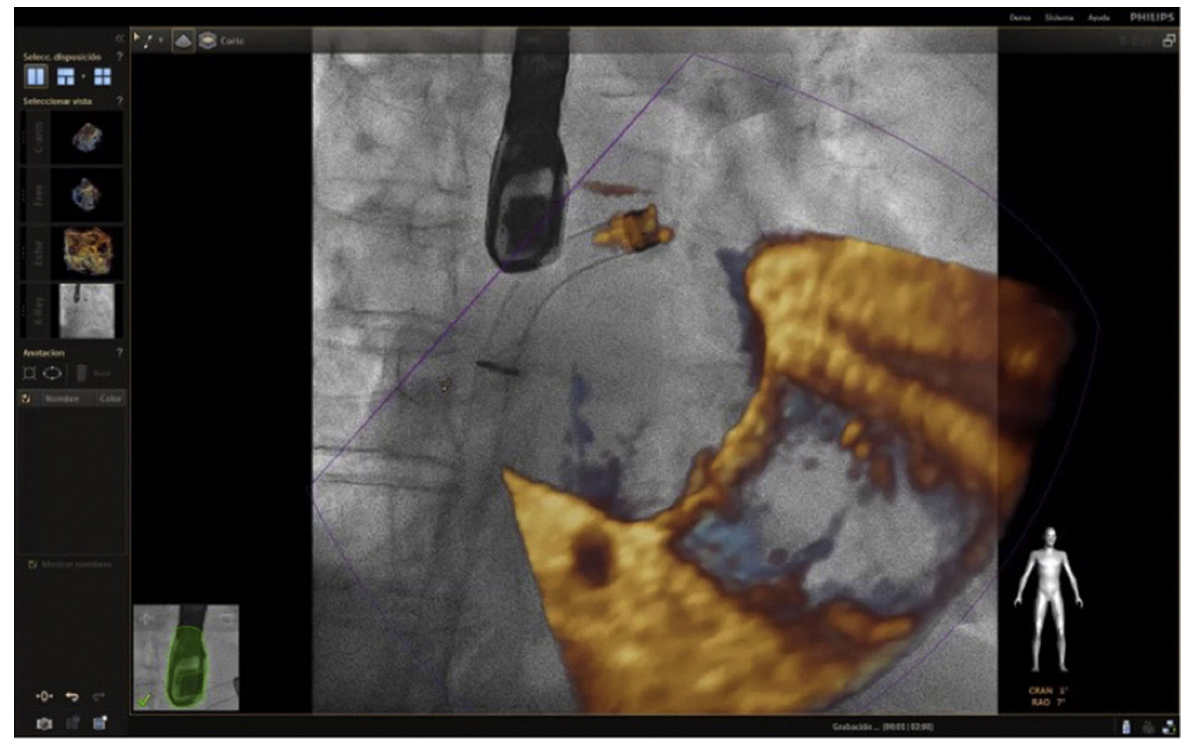

Figura 3 Imagen de fusión. Se observa paso de camisa en el septo interauricular comenzando giro hacia la válvula mitral para colocación de Mitraclip.

ubicar la sonda centrada el máximo posible en el campo visual teniendo en cuenta que a partir de allí se obtiene la sincronización del registro). La confirmación de la ubicación del co-registro de la sonda se puede ver representada de dos maneras: color verde si es adecuada o rojo si no lo es (fig. 4); el tercer cuadrante está dedicado a la imagen fusionada (el flujo del haz del transductor está graficado sobre la imagen en la cual todo cambio de posición, angulación o rotación de la sonda inmediatamente es registrado y actualizado en la fluoroscopia); por último, el cuarto cuadrante se encuentra libre para visualizar la imagen de referencia a discreción de los operadores.

Es importante recalcar que las funciones del ecocardiograma transesofágico se pueden emplear en sus diferentes

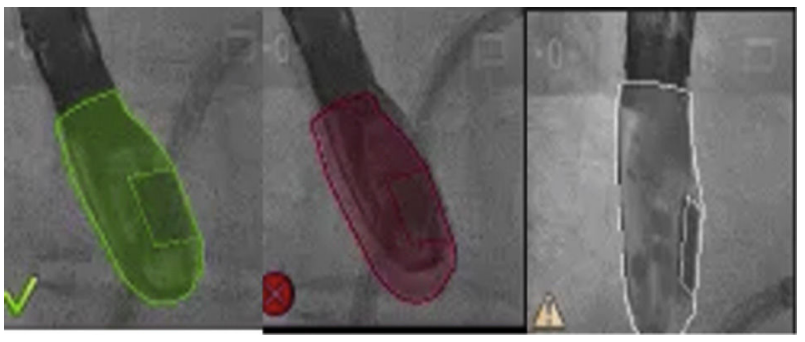

Figura 4 Registro de la sonda transesofágica en el extremo de la pantalla del fluoroscopio (verde: registro adecuado, rojo: pérdida del registro, blanco: se desconoce el registro por inactividad).

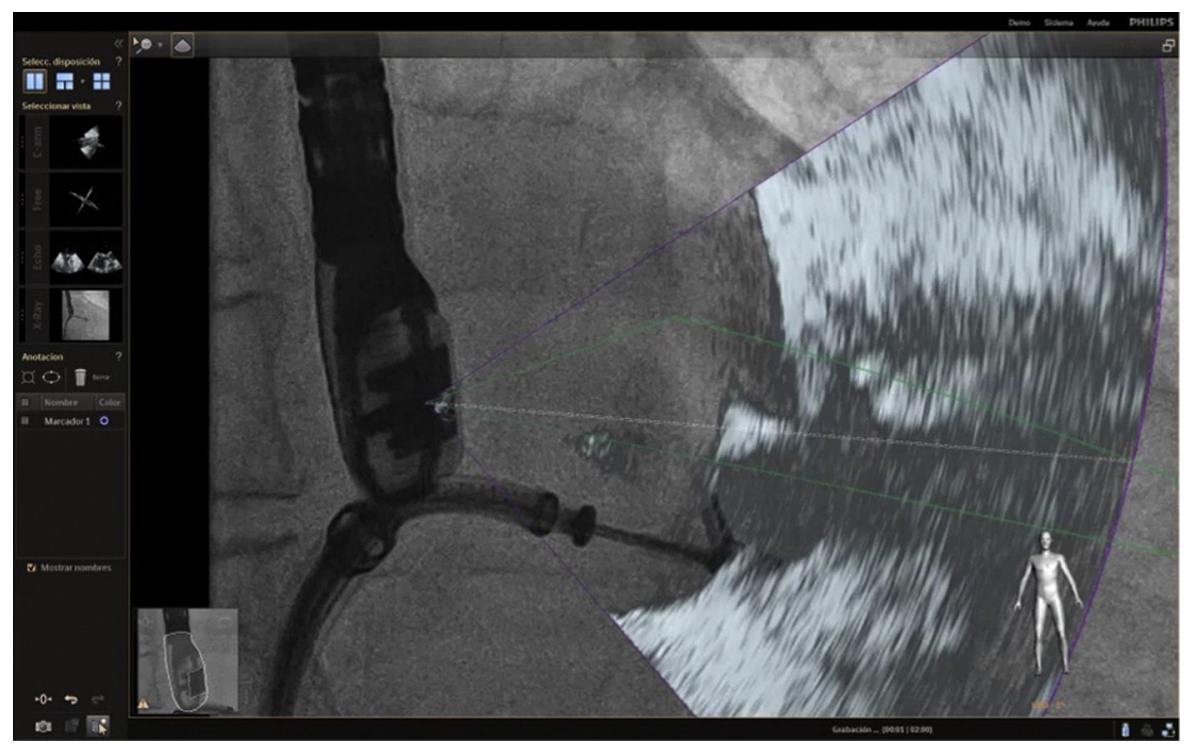

Figura 5 Imagen de fusión. Durante la maniobra de colocación del Mitraclip se observa pérdida de registro de la sonda respecto al fluoroscopio. 


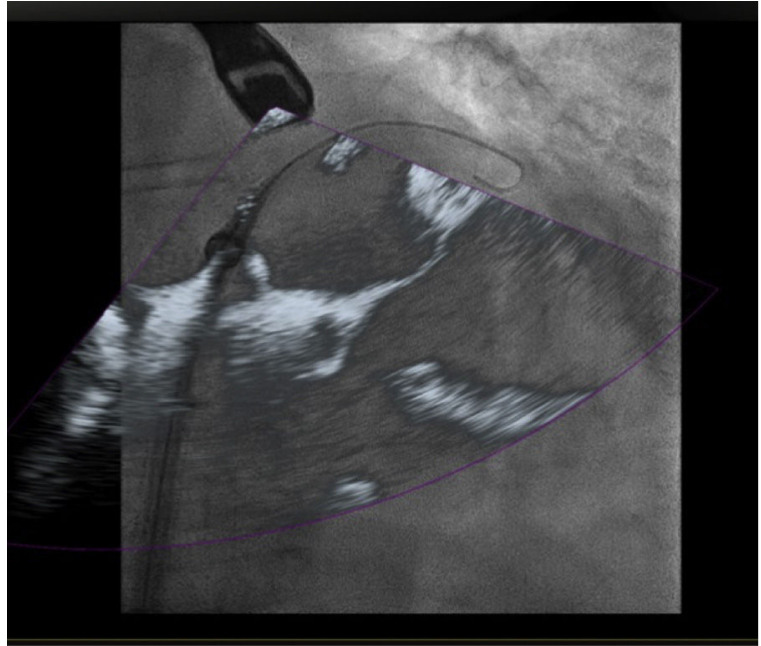

Figura 6 Imagen de fusión. Plano bicavo; previo a punción septal se colocó marcador en fluoroscopio para guía por parte del intervencionista.

modalidades tales como 2D, $3 \mathrm{D}$ y color Doppler, así como la integración de visualización en x-plane, 3D zoom y $3 \mathrm{D}$ Full volumen.

Con el advenimiento del intervencionismo estructural, una de las herramientas más importantes y que hacen de la fusión de imágenes un gran atractivo en la actualidad ${ }^{8}$, es la posibilidad de ubicar marcadores para identificar puntos o regiones de interés para el intervencionista y al mismo tiempo trasladar la información del ecocardiograma a la imagen de fluoroscopia.

Las imágenes multiplanares en $3 \mathrm{D}$ ofrecen una localización precisa, razón por la cual es la modalidad más recomendada en la práctica actual. Una vez se realiza la marcación del sitio de interés este aparecerá en la imagen de fluoroscopia que permanecerá fija sin importar el movimiento de la sonda ni del gantry. No obstante, se debe tener

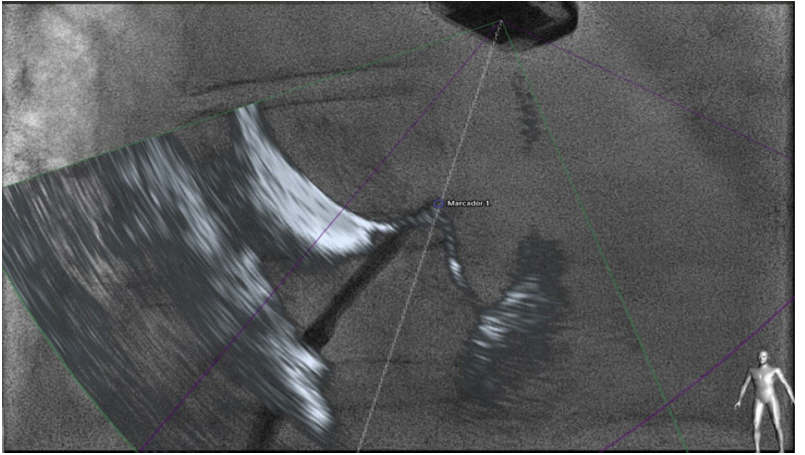

Figura 7 Imagen de fusión. Se observa en ventana bicava con ecocardiografía 3D punción septal en el paso de guía para implante de Mitraclip.

precaución con los movimientos verticales (mesa) influyentes en la pérdida de los marcadores, lo cual llevaría a un reinicio del registro y posicionamiento de la sonda.

Con base en lo anterior es importante mencionar que existen tres posibles causas por las cuales se podría desajustar el registro: cuando la sonda lleva mucho tiempo sin ser registrada (fig. 5.) y debido a algún movimiento del brazo - la mesa se pierden todos los puntos de referencia marcados; otra es la naturaleza estática de los marcadores los cuales no responden a los movimientos traslacionales como la respiración, y por último, pequeños movimientos durante el procedimiento que causan desajustes.

\section{Consideraciones en procedimientos de intervención estructural cardiaca}

De acuerdo con las ventajas de la imagen de fusión dinámica Echonavigator ${ }^{\circledR}$ y la utilización de esta en múltiples procedimientos $^{15,16}$, a continuación se presentan cada uno de los aspectos más importantes y el estado del arte actual,

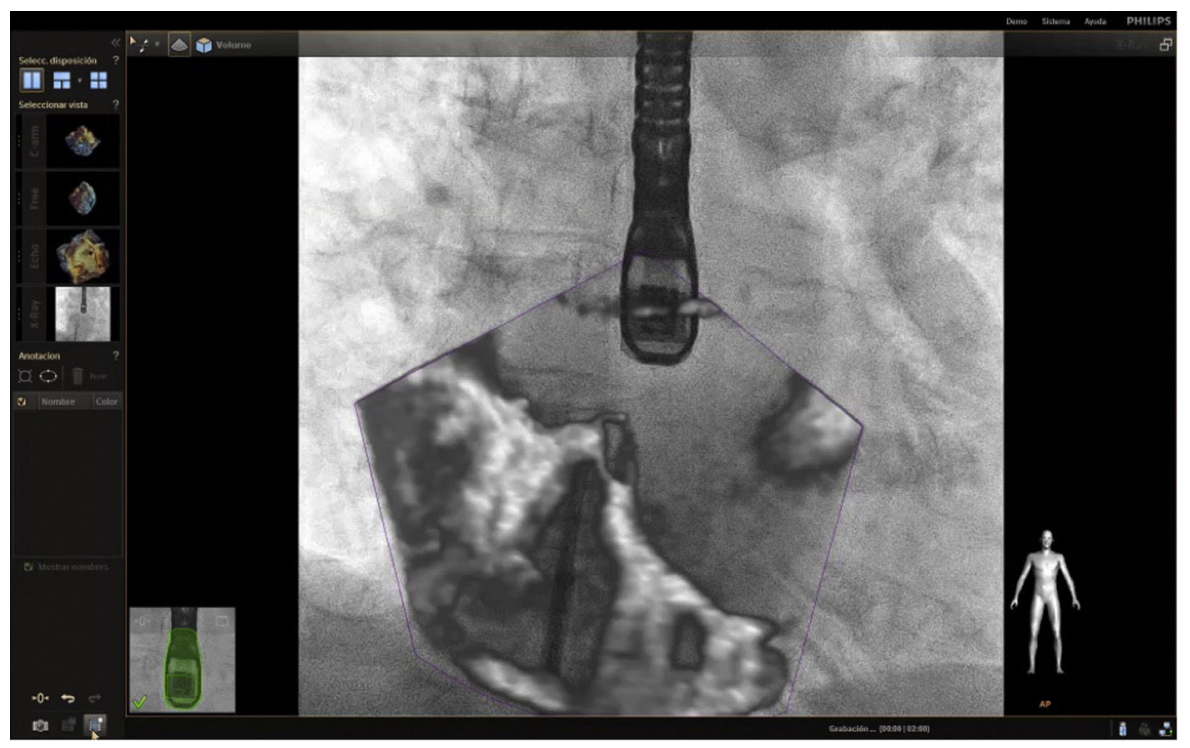

Figura 8 Se observa en proyección bicava por ecocardiografía transesofágica $3 \mathrm{D}$ el marcador en la pantalla de fluoroscopio como guía en el momento previo a la punción del septo interauricular. 
que podría variar en el transcurso de los años a medida que se emplee con mayor frecuencia.

\section{Punción transeptal}

Es el paso crítico primario en muchas de las intervenciones estructurales. Esta requiere una exactitud milimétrica para evitar complicaciones relacionadas por la proximidad a estructuras vitales ${ }^{8}$. Para esto se marca un punto de referencia en la imagen de fluoroscopia (fig. 6); de acuerdo con el procedimiento la punción puede ser inferoposterior (cierre de orejuela izquierda) o anterosuperior $(4 \mathrm{~cm}$ por encima del anillo mitral en caso de la implantación de Mitraclip).

Es viable emplear dos opciones de visualización; la vista bicava sobrepuesta en la fluoroscopia, que ofrece una opción rápida y segura en la punción del septo interatrial (figs. 7 y 8), o una imagen de cuatro cámaras a $0^{\circ}$ para medir las distancias requeridas según el procedimiento; sin embargo, en el momento de la punción se debe incrementar el ángulo a $45^{\circ}$ y activar la función multiplanar para seguimiento. La primera opción es más común y arroja buenos resultados de seguridad $^{2}$. Recientemente, Afzal et al., evaluaron la seguridad y eficacia de la punción guiada por imagen de fusión e informaron que no hubo efectos adversos en el empleo de la técnica y el tiempo de realización fue significativamente menor en el grupo de fusión ${ }^{17}$.

\section{Oclusión de la orejuela izquierda}

La intervención de cierre de la orejuela izquierda ha mostrado ser una alternativa efectiva a la anticoagulación oral ${ }^{18}$ y aunque en teoría el procedimiento se puede hacer sin asistencia de imagen, las múltiples ventajas con ecocardiografía transesofágica $3 \mathrm{D}$ han sido demostradas en estudios recientes ${ }^{19}$. Durante este procedimiento, inicialmente se aplica la técnica previa de ubicación de punto de referencia

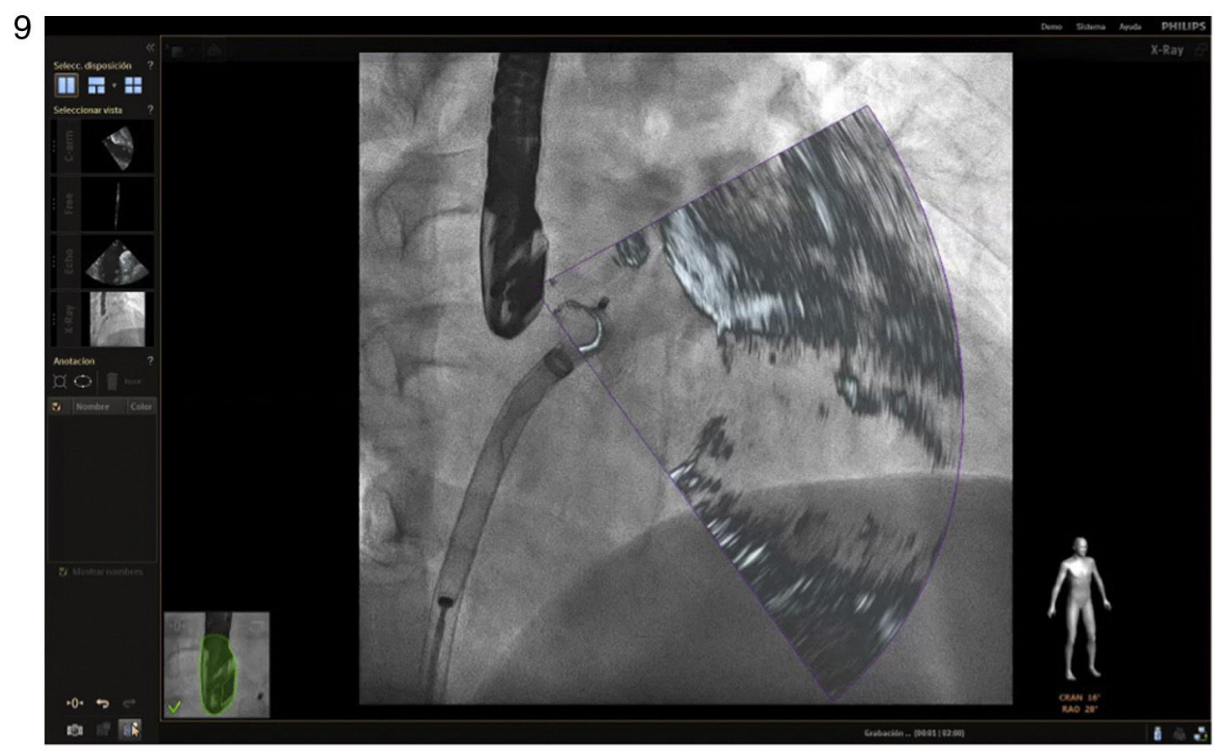

10

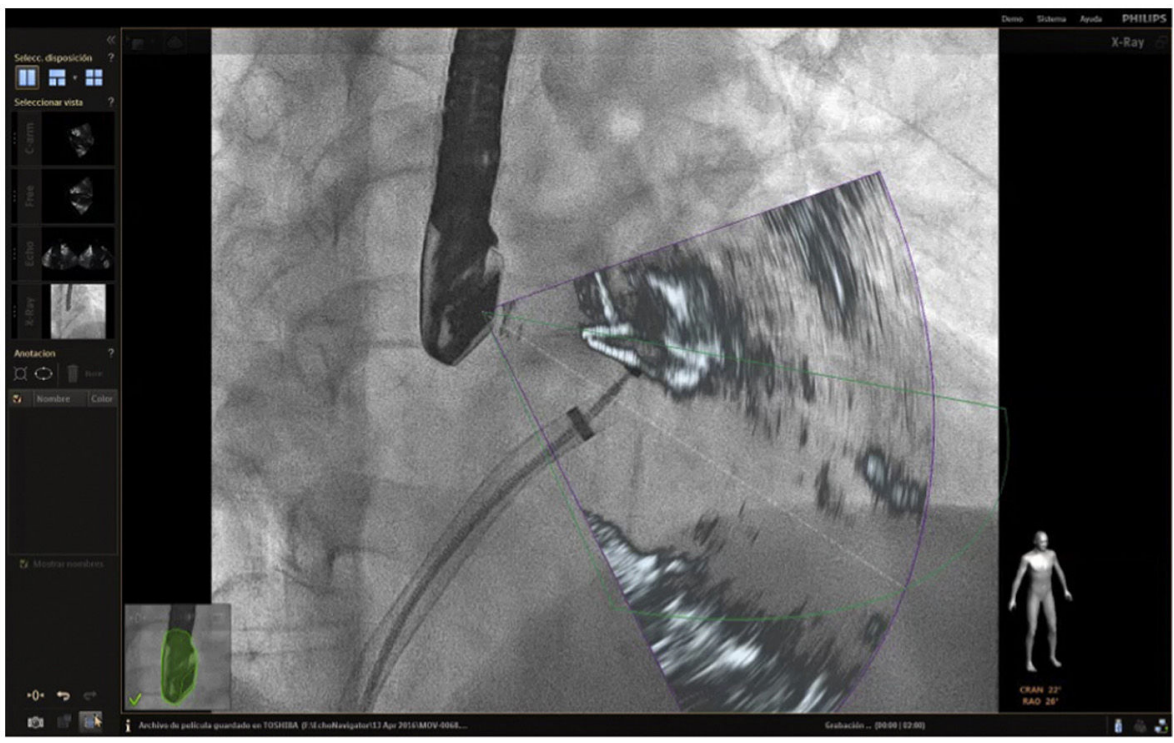

Figuras 9 y 10 Imagen de fusión. Se observa paso de guía a través del septo auricular dirigido a la orejuela izquierda durante implante del dispositivo. 


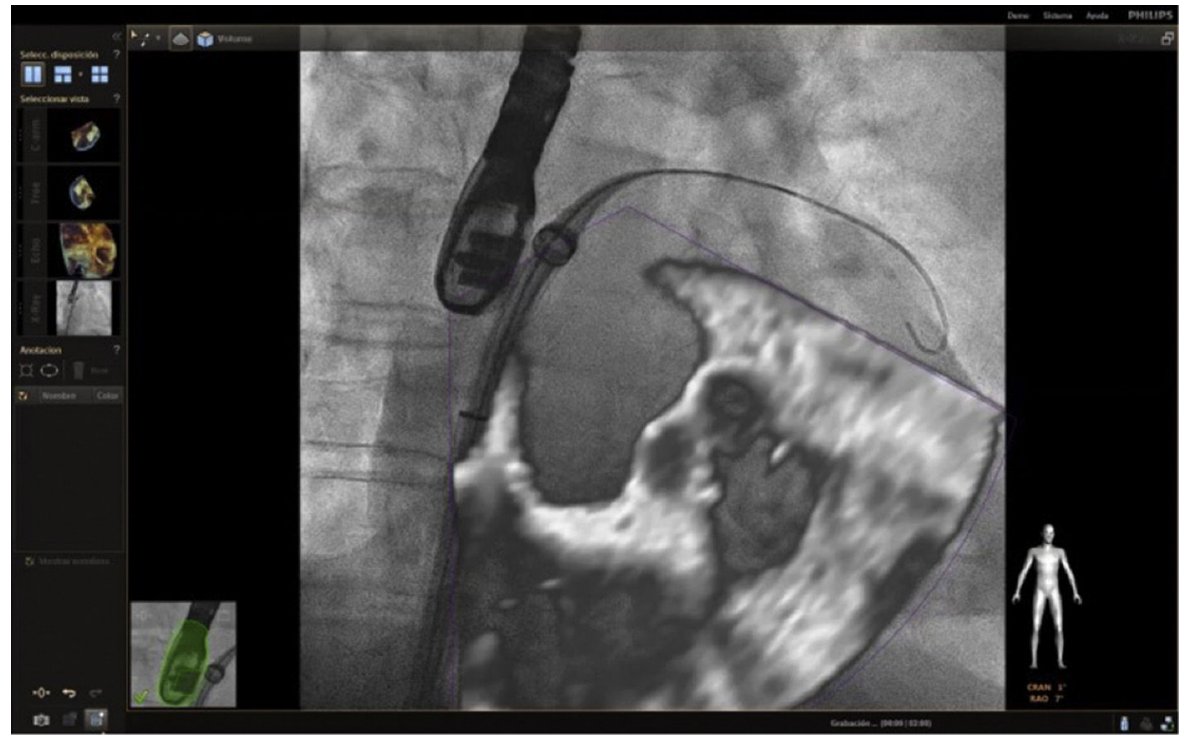

Figura 11 Imagen de fusión. Procedimiento de colocación de Mitraclip. Paso de guía a la vena pulmonar izquierda para soporte del dispositivo.

para punción transeptal teniendo en cuenta las potenciales complicaciones derivadas, como la perforación de la orejuela izquierda y la laceración de la arteria pulmonar, que pueden llevar a taponamiento pericárdico y descenlace mortal. La guía de canulación por 2D/3D en visión multiplanar se realiza entre $70^{\circ}$ y $90^{\circ}$ a través de la aurícula izquierda, que lleva al siguiente marcador que va dirigido a localizar el orificio de entrada de la orejuela izquierda, la arteria coronaria circunfleja y/o el orificio de la vena pulmonar superior izquierda, puntos de referencia y seguridad para la realización del procedimiento (figs. 9 y 10). Adicionalmente, ofrece una imagen dinámica para la orientación y posición correcta del dispositivo ${ }^{14,20}$. Jungen et al., evaluaron un grupo de 34 pacientes a quienes se les implantó un dispositivo mediante la imagen por fusión. Concluyeron que hubo una reducción de la dosis de radiación en un $48 \%$ y tiempo de fluoroscopia en un $33 \%$ respecto al procedimiento usual; como datos adicionales, la técnica no se vio afectada por aumento de complicaciones o tiempo de ejecución ${ }^{21,22}$.

\section{Reparación mitral transcatéter (Mitraclip)}

En la actualidad, la implantación de Mitraclip se acepta como una alternativa en el tratamiento de la insuficiencia mitral para pacientes con alto riesgo quirúrgico ${ }^{23}$. Los pasos críticos en el éxito del procedimiento son la punción transeptal y la colocación del Mitraclip. La ecocardiografía 2D/3D es la modalidad de elección durante el procedimiento.

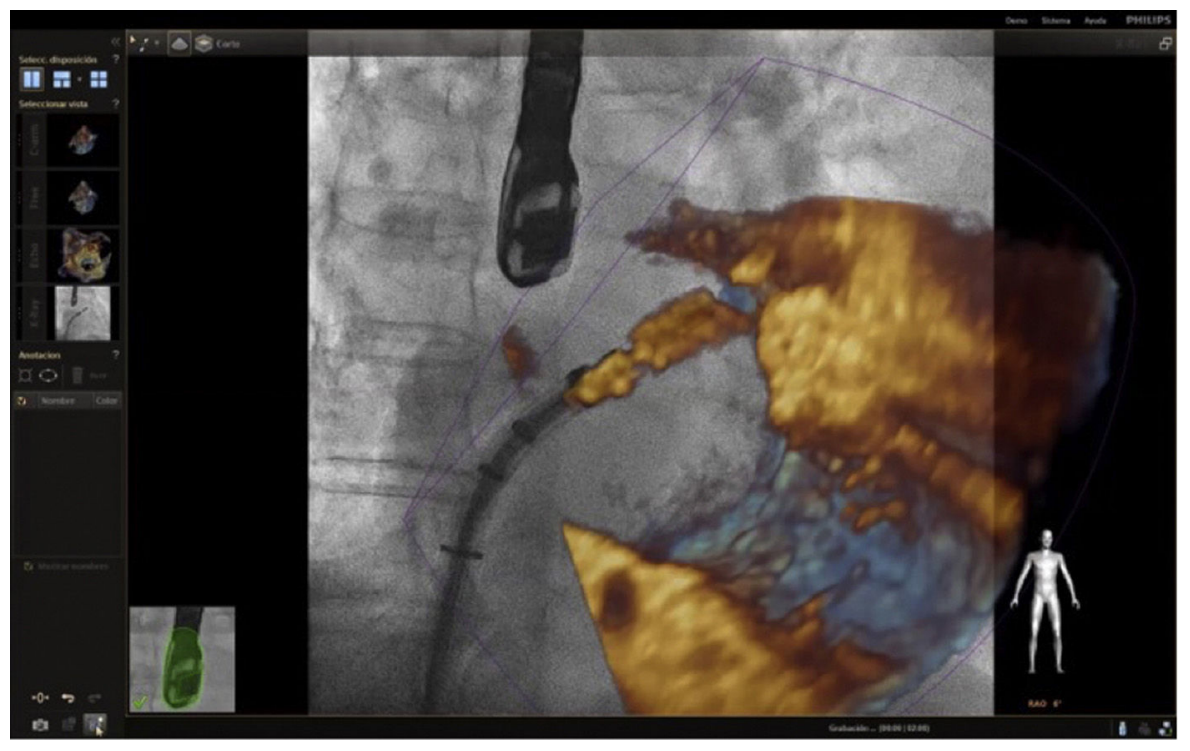

Figura 12 Imagen de fusión. Procedimiento de colocación de Mitraclip. Paso de clip a través del catéter e inicio de maniobra de giro hacia la válvula mitral. 


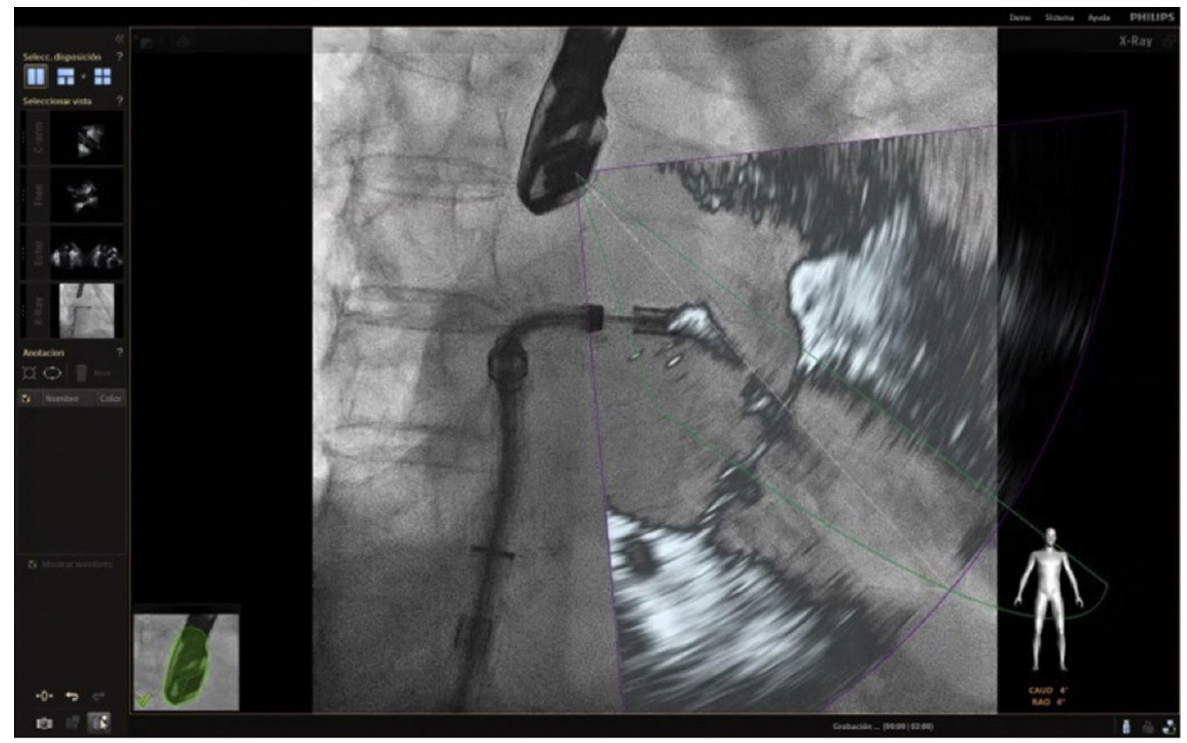

Figura 13 Imagen de fusión. Procedimiento de colocación de Mitraclip. Clip que gira dentro de la aurícula izquierda buscando ángulo de $90^{\circ}$ respecto a la válvula mitral.

Previamente se mencionó la técnica empleada en la punción septal; en cuanto a su utilidad como guía (fig. 11), la fusión de imagen desempeña un papel fundamental en la trayectoria inicial del clip en la entrada a la aurícula y luego su orientación en el objetivo de alcanzar una posición ideal en la válvula mitral (figs. 12-15).

La designación de tres puntos de orientación (sitio de punción en el septum interatrial, ligamento de Marshall entre la vena pulmonar y la orejuela izquierda y centro de la válvula mitral), puede prevenir lesiones en la aurícula izquierda y un adecuado posicionamiento del clip. Sundermann et al., evaluaron 21 pacientes llevados a Mitraclip midiendo el tiempo de radiación y extensión de procedimiento. Concluyeron menor exposición a radiación y tiempo de procedimiento no menor al comparador ${ }^{24}$.

\section{Cierre de leak perivalvular}

Se han propuesto múltiples técnicas como guía de procedimiento en los cierres de leaks perivalvulares ${ }^{25}$; sin embargo, el ecocardiograma $3 \mathrm{D}$ transesofágico ofrece resolución espacial excelente en la ubicación del defecto (o los defectos), que hace de esta la herramienta más útil en este tipo de procedimientos. Adicionalmente, sirve de apoyo en el paso de la guía a través del defecto y logra mostrar

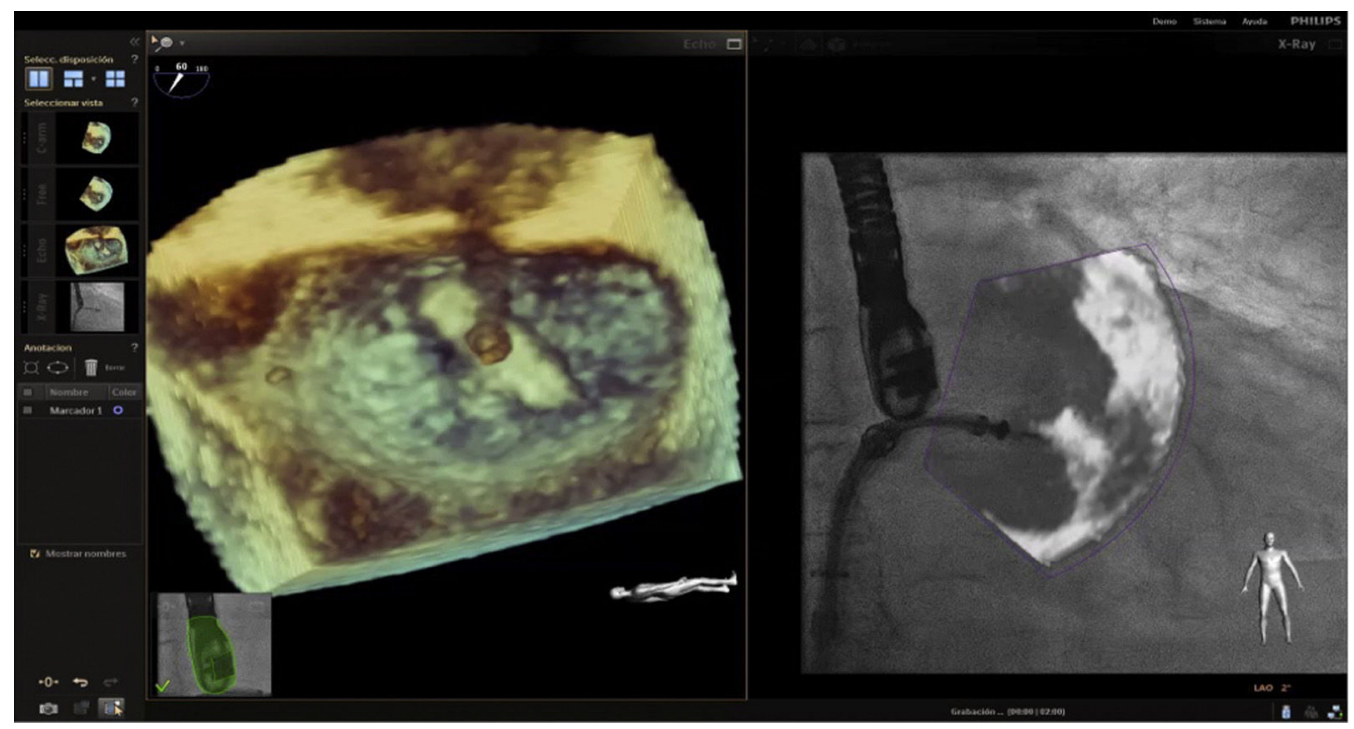

Figura 14 Imagen de fusión. Procedimiento de colocación del Mitraclip. A la izquierda se observa imagen de ecocardiograma $3 \mathrm{D}$ desde la aurícula posicionando Mitraclip, con leve giro antihorario respecto al eje de la comisura mitral. A la derecha, proximidad del dispositivo a la válvula mitral en tiempo real respecto a la imagen de la izquierda. 


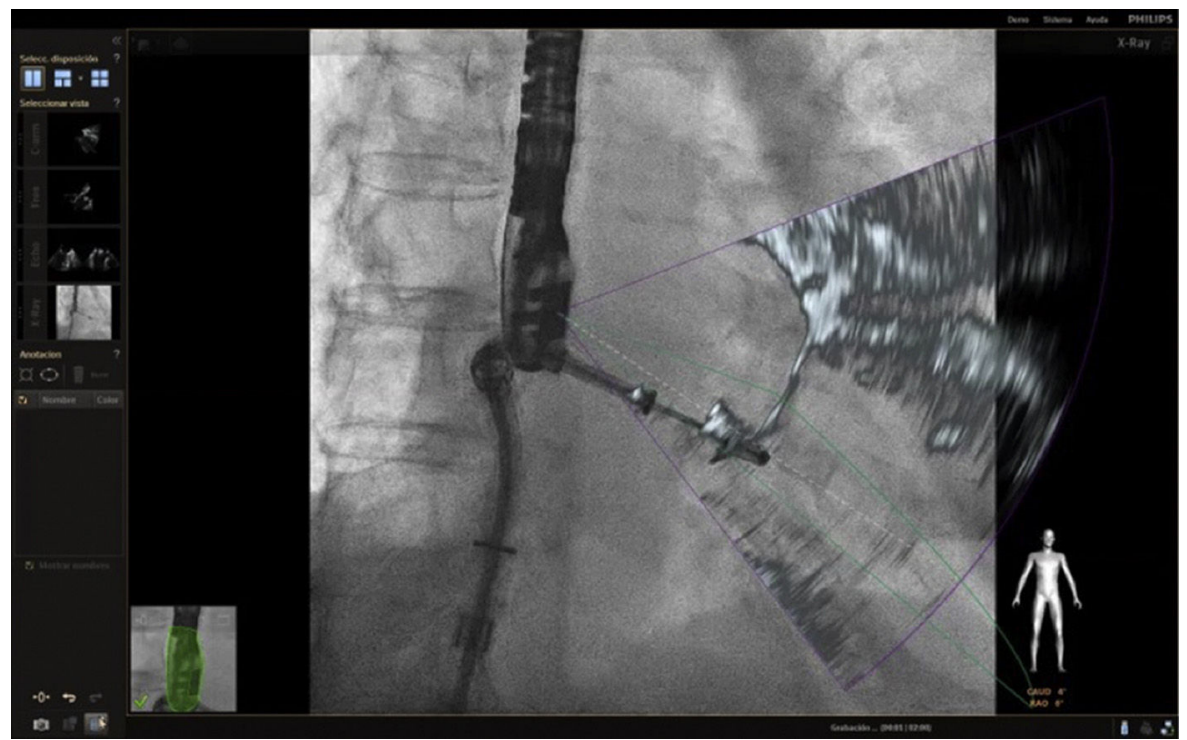

Figura 15 Imagen de fusión. Procedimiento de colocación del Mitraclip. Se observa paso a través de la válvula mitral del dispositivo ya alineado.

cualquier interacción entre la guía y la válvula, con lo cual pueden vigilarse los posibles daños a la misma. Cuando se añade la tecnología de fusión, se emplea la herramienta de marcadores en el sitio exacto de paso de la guía, en especial en defectos muy pequeños. Sin embargo, cuando se trata de leaks aórticos puede llegar a ser un poco más difícil teniendo en cuenta el movimiento traslacional de la raíz aórtica.

\section{Reemplazo aórtico transcatéter (TAVR)}

En el implante transcatéter de la válvula aórtica es fundamental el conocimiento exacto de la anatomía de la raíz aórtica, los senos de Valsalva y el ostium de las arterias coronarias. Se ha recurrido en los últimos años a la fusión de imágenes de tomografía computarizada ${ }^{26}$, fluoroscopia (con el fin de obtener los puntos de referencia antes mencionados a lo largo de todo el procedimiento) (fig. 16) y seguimiento por ecocardiografía transesofágica 2D/3D (que puede ser limitado por la obstrucción parcial en el campo visual de la fluoroscopia).

Sin embargo; debe tenerse en cuenta que la imagen tomográfica es estática, tiene una compensación de movimiento insuficiente la cual es susceptible a errores por movimiento traslacionales del paciente, y puede inducir a errores. En este punto, la fusión en tiempo real de ecocardiografía y fluoroscopia da en todo momento la referencia de los puntos en bisagra de la válvula aórtica alineados, necesarios para una técnica precisa (fig. 17).

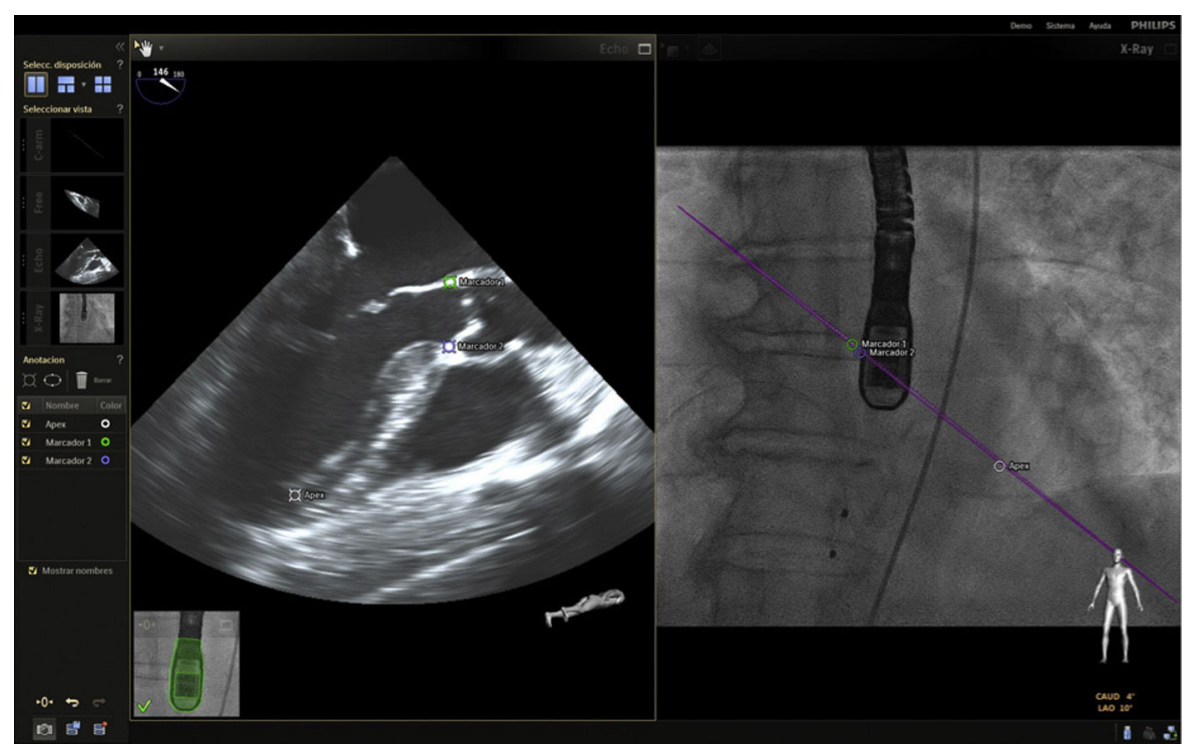

Figura 16 Imagen de fusión. Procedimiento de colocación de prótesis aórtica por vía percutánea (TAVI). Colocación de marcadores de aorta y válvula mitral. 


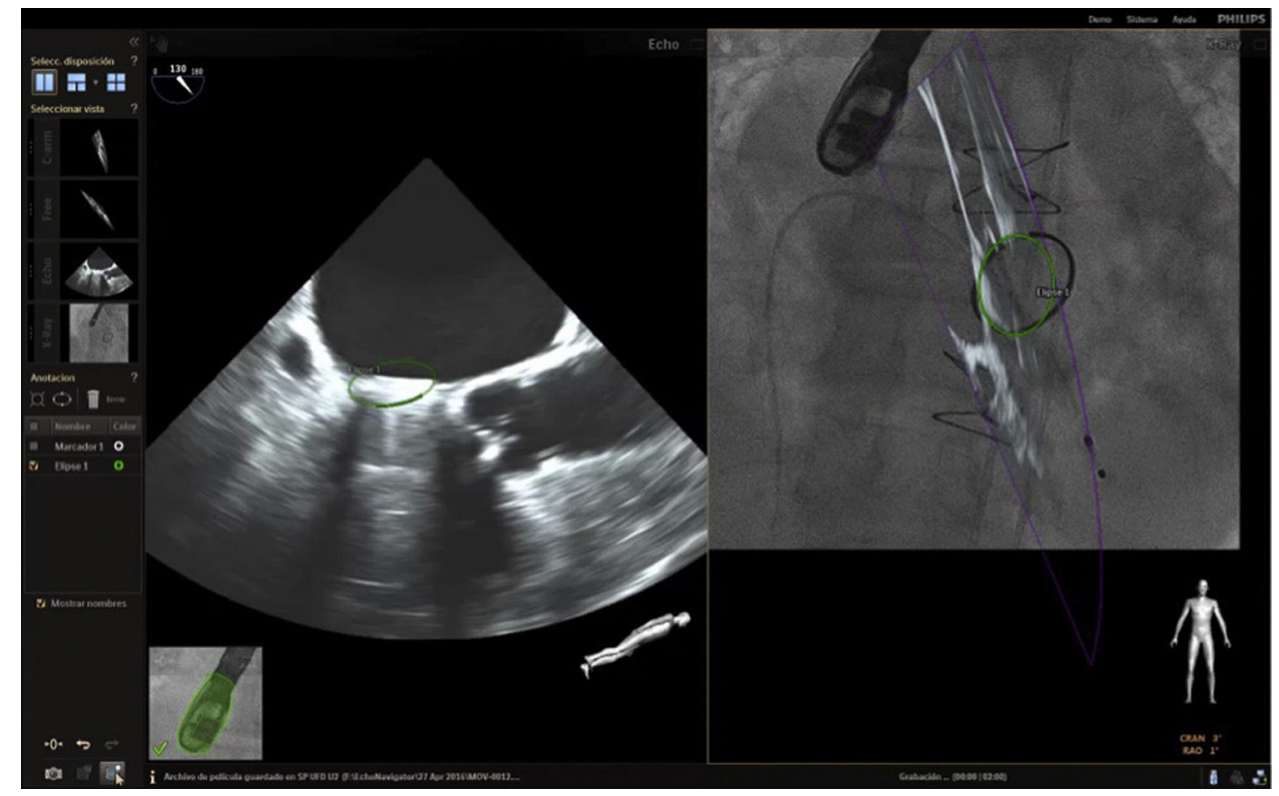

Figura 17 Imagen de fusión. Se ubica referencia en fluoroscopio de prótesis mitral como apoyo para intervencionismo durante paso de guías en colocación de prótesis aórtica por vía percutánea (TAVI).
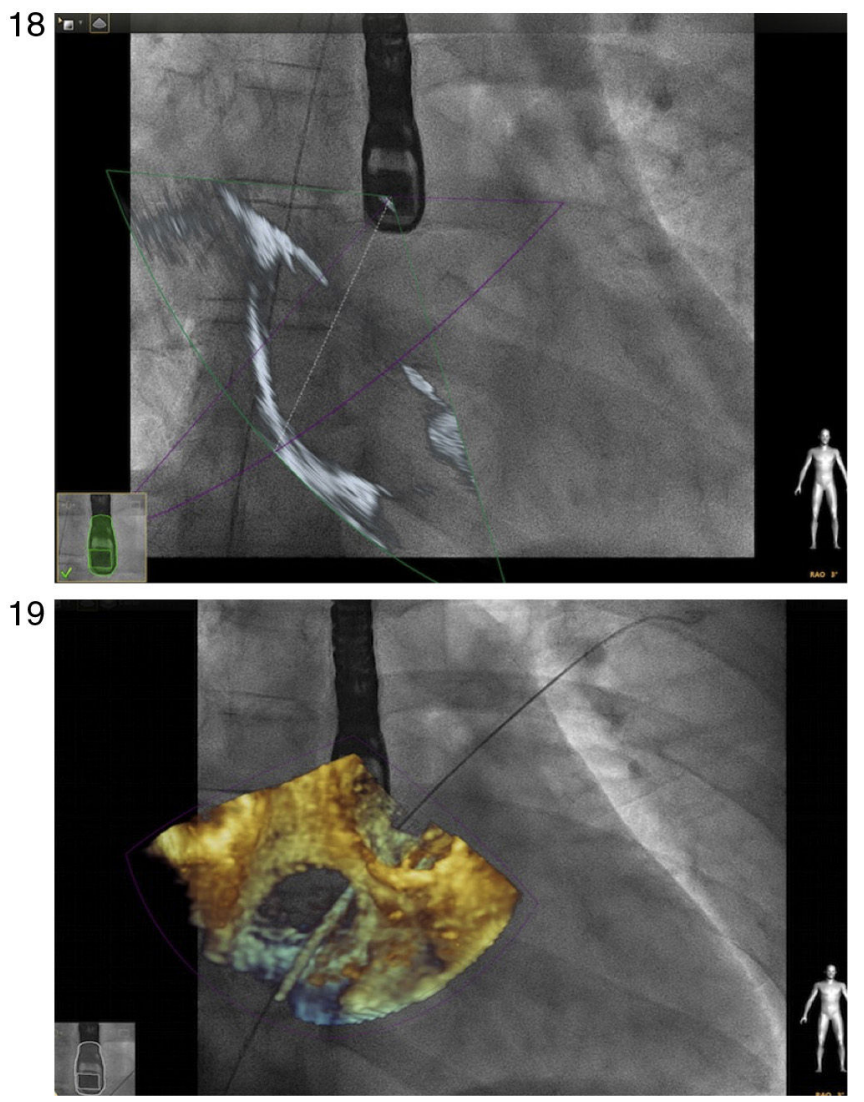

Figuras 18 y 19 Imagen de fusión. Evaluación previa a colocación de dispositivo para cierre de defecto interauricular. Se muestran las relaciones anatómicas con una exactitud milimétrica.

\section{Comunicaciones interauriculares}

El procedimiento de cierre de foramen ovale y defectos septales, ha sido guiado tradicionalmente mediante fluoroscopia y ecocardiograma transesofágico como guía de imagen. Más recientemente, Balzer et al. ${ }^{27}$ validaron la eficacia y seguridad del uso de imagen en $3 \mathrm{D}$ dando mayor calidad de imagen y posicionamiento del catéter respecto a 
las estructuras subyacentes con menor exposición a radiación que en el procedimiento cotidiano. La experiencia inicial en nuestro grupo y en los grupos que están iniciando la técnica, muestra que ésta ofrece información adicional en los puntos de referencia para el paso de la guía, a la vez que brinda seguridad en el momento de la liberación del dispositivo, ya que hay un control constante del defecto (figs. 18 y 19).

\section{Cardiopatías congénitas}

Recientemente Jone et al. ${ }^{28}$, evaluaron una población de pacientes con cardiopatías congénitas susceptibles de intervención percutánea abarcando en su mayoría población infantil (media edad 9 años) con patologías diversas que incluyeron cierre de defectos atriales, cierre de penetración de Fontan, cierre de defectos ventriculares, angioplastias etc, cuyos resultados fueron disminución de tiempo de fluoroscopia y dosis de radiación.

\section{Experiencia actual}

En el Servicio de Cardiología del Hospital Clínico San Carlos se han implantado TAVI, dispositivos Mitraclip y dispositivos de cierre de orejuela izquierda y se han llevado a cabo procedimientos de cierre de dehiscencias periprotésicas. Desde 2015 se emplea el Echonavigator ${ }^{\circledR}$ de forma rutinaria en todos estos procedimientos.

\section{Limitaciones}

Las limitaciones actuales están basadas en la aparición reciente de la tecnología, de modo que los datos de estudios son pocos, aunque todos muestran resultados superiores en cuanto a seguridad, disminución de exposición a radiación y tiempo de realización del procedimiento respecto al procedimiento estándar ${ }^{14,28}$; otro factor importante es que solo se cuenta con un sistema comercialmente operativo en este momento. No obstante, a medida que su uso se expanda habrá mayor información disponible para corroborar estos datos iniciales.

Puede presentarse un error potencial en el registro en el momento en que el marcador se encuentra en la dirección del fluoroscopio, el cual se puede mitigar con un mejor posicionamiento de la imagen $3 \mathrm{D}$.

Como es usual, en nuevas tecnologías la curva de aprendizaje es importante ya que manipular la imagen de la ecocardiografía y del sistema de función puede llegar a ser un reto para el especialista.

\section{Conclusión}

La fusión de la ecocardiografía 2D/3D con fluoroscopia a través de un software especialmente diseñado (Echonavigator $^{\circledR}$ ), ofrece la posibilidad de realizar procedimientos de intervencionismo cardiaco de una forma más segura, rápida y con menor dosis de irradiación. Permite al cardiólogo intervencionista evaluar de forma precisa la intervención con anatomía tridimensional superpuesta en la imagen de fluoroscopia. Todos los procedimientos de intervencionismo cardiaco tienen el potencial de beneficiarse de esta tecnología, y tal vez sean de mayor utilidad en los casos más complejos y demandantes para el intervencionista. La mejor visualización tridimensional y en tiempo real de las relaciones anatómicas, acortará la curva de aprendizaje de los médicos en entrenamiento de intervencionismo estructural. La terapia cardiovascular con intervencionismo cardiaco seguirá presentado un crecimiento exponencial similar al que tuvo la cirugía cardiovascular en sus inicios. El número de pacientes con intervencionismo estructural será cada vez mayor. Hay un gran interés en ensayar nuevos dispositivos percutáneos para el tratamiento de todo tipo de insuficiencia y estenosis valvular. La variedad de nuevas válvulas biológicas para implantación percutánea, ha tenido un crecimiento vertiginoso en los últimos años. Todos estos avances terapéuticos requieren que los métodos de imágenes sean cada vez más ágiles, dinámicos, seguros y de mayor precisión estructural. El futuro de la imagen de fusión posiblemente radicará en desarrollar software de reconstrucción tridimensional con resolución temporal y espacial óptima además de adquisición estándar en un solo latido, en el cual la interferencia por arritmias o por artefactos de movimiento sea mínima o inexistente, o software con algoritmos que corrijan de forma inmediata los artefactos por movimiento o por desfase de los dos métodos de imagen. La imagen de fusión ya está en la arena clínica. Su utilidad está siendo evaluada y sustentada por los grupos de cardiología que la utilizan en su práctica rutinaria.

\section{Responsabilidades éticas}

Protección de personas y animales. Los autores declaran que para esta investigación no se han realizado experimentos en seres humanos ni en animales.

Confidencialidad de los datos. Los autores declaran que han seguido los protocolos de su centro de trabajo sobre la publicación de datos de pacientes.

Derecho a la privacidad y consentimiento informado. Los autores declaran que en este artículo no aparecen datos de pacientes.

\section{Conflicto de interés}

Ninguno.

\section{Bibliografía}

1. Herrmann H, Baxter S, Ruiz C, Feldman T, Hijazi Z. Results of the society of cardiac angiography and interventions survey of physicians and training directors on procedures for structural and valvular heart disease. Catheterization and Cardiovascular Interventions. 2010;76:E106-10.

2. Biaggi P, Fernandez-Golfin C, Hahn R, Corti R. Hybrid imaging during transcatheter structural heart interventions. Curr Cardiovasc Imag Reports. 2015;8:33.

3. Smith CR, Leon MB, Mack MJ, Miller C, Mosses J, Svensson L, et al. Transcatheter versus surgical aortic-valve replacement in high-risk patients. N Eng J Med. 2011;364:2187-98.

4. Reddy VY, Sievert H, Halperin J, Doshi SK, Buchbinder M, Neuzil $\mathrm{P}$, et al. Percutaneous left atrial appendage closure vs. 
warfarin for atrial fibrillation: a randomized clinical trial. JAMA. 2014;312:1988-98.

5. Maisano F, Franzen O, Baldus S, Schaffer U, Hausleiter J, Butter $\mathrm{C}$, et al. Percutaneous mitral valve interventions in the real world: early and 1-year results from the ACCESS EU; a prospective, multicenter, nonrandomized postapproval study of the MitraClip therapy in Europe. J Am Coll Cardiol. 2013;62:1052-61.

6. Clegg S, Salcedo E, Quaife R, Carrol J. Imaging in structural heart disease. En: Lasala J, Rogers J, editores. Interventional procedures for adult and structural heart disease. 1 st. ed. Elsevier-Saunders; 2014. p. 7-28.

7. Carminati M, Agnifili M, Arcidiacono C, Brambilla N, Bussadori C, Butera G, et al. Role of imaging in interventions on structural heart disease. Exp Rev Cardiovasc Ther. 2013;11: 1659-76.

8. Thaden J, Sanon S, Geske J, Eleid M, Nijhof N, Malouf J, et al. Echocardiographic and fluoroscopic fusión imaging for procedural guidance: An overview and early clinical experience. J Am Soc Echocardiography. 2016;29:503-12.

9. Gaemperli O, Schepis T, Kalff V, Nambar M, Valenta I, Stefani L, et al. Validation of a new cardiac image fusion software for three-dimensional integration of myocardial perfusion SPECT and stand-alone 64-slice CT angiography. Eur J Nuclear Med Molecular Imaging. 2007;34:1097-106.

10. White JA, Fine N, Gula LJ, Yee R, Al-admawi M, Zhang Q, et al. Fused whole-heart coronary and myocardial scar imaging using 3-TCMR. Implications for planning of cardiac resynchronization therapy and coronary revascularization. JACC Cardiovascular Imaging. 2010;3:921-30.

11. Tanis W, Scholtens A, Habets J, Van den brink RB, van Herwerden LA, Chamuleau SA, et al. CT angiography and (1)(8) FFDGPET fusion imaging for prosthetic heart valve endocarditis. JACC Cardiovascular Imaging. 2013;6:1008-13.

12. Krishnaswamy A, Tuzcu EM, Kapadia SR. Integration of MDCT and fluoroscopy using C-arm computed tomography to guide structural cardiac interventions in the cardiac Catheterization laboratory. Catheterization and Cardiovascular Interventions. 2015;85:139-47.

13. Arujuna A, Housden R, Ma Y, Rajani R, Gao G, Nijhof N. Novel system for real-time integration of $3 \mathrm{D}$ echocardiography and fluoroscopy for image-guided cardiac interventions: preclinical validation and clinical feasibility evaluation. IEEE.JTEHM. 2014:2:110.

14. Balzer J, Zeus T, Hellhammer K, Veulemans V, Eschenhagen $\mathrm{S}$, Kehmeier $\mathrm{E}$, et al. Initial clinical experience using the Echonavigator ${ }^{\circledR}$-system during structural heart disease interventions. World J Cardiol. 2015;7:562-70, 26

15. Feldman T, Hellig F, Mollman H. Structural heart interventions: the state of the art and beyond. Eurointervention. 2016;12:X6.

16. Palacios I, Arzamendi D. Intervencionismo en cardiopatía estructural. Más allá de la terapia valvular transcateter. Rev Esp Cardiol. 2012;65:405-13.

17. Afzal S, Veulemans V, Balzer J, Rassaf T, Hellhammer K, Polzin $A$, et al. Safety and efficacy of transseptal puncture guided by real-time fusion of echocardiography and fluoroscopy. Netherland Heart Journal. 2016. Epub ahead of print.

18. Reddy VY, Doshi SK, Sievert H, Buchbinder M, Neuzil P, Huber $\mathrm{K}$, et al. Percutaneous left atrial appendage closure for stroke prophylaxis in patients with atrial fibrillation: 2.3-year followup of the PROTECT AF (Watchman Left Atrial Appendage System for Embolic Protection in Patients with Atrial Fibrillation) Trial. Circulation. 2013;127:720-9.

19. Nucifora G, Faletra FF, Regoli F, Pasotti E, Pedrazzini G, Moccetti $T$, et al. Evaluation of the left atrial appendage with realtime 3-dimensional transesophageal echocardiography: implications for catheter-based left atrial appendage closure. Circulation Cardiovascular Imaging. 2011;4:514-23.

20. Gafoor S, Schulz P, Heuer L, Matic P, Franke J, Bertog S, et al. Use of Echo-Navigator, a novel echocardiography-fluoroscopy overlay system, for transseptal puncture and left atrial appendage occlusion. J Int Cardiol. 2015;28:215-7.

21. Jungen C, Zeus T, Balzer J, Eickholt C, Petersen M, Kehmeier $\mathrm{E}$, et al. Left atrial appendage closure guided by integrated echocardiography and fluoroscopy imaging reduces radiation exposure. Plos One. 2015;10:1-13.

22. Garcia-Fernandez M, De Agustin A, Perez de Isla L. Eco-Xray fusion in left atrial appendage closure. Rev Esp Cardiol. 2016. Article in press.

23. Vahanian A, Alfieri O, Andreotti F, Antunes MJ, Barón-Esquivias G, Baumgartner H. ESC Committee for Practice Guidelines (CPG); Joint Task Force on the Management of Valvular Heart Disease of the European Society of Cardiology (ESC); European Association for Cardio-Thoracic Surgery (EACTS). Guidelines on the management of valvular heart disease: the Joint Task Force on the Management of Valvular Heart Disease of the European Society of Cardiology (ESC) and the European Association for Cardio-Thoracic Surgery (EACTS). Eur J Cardiothorac Surg. 2012;42:S1-44.

24. Sundermann S, Biaggi P, Grunenfelder J, Gessat M, Felix C, Bettex D. Safety and feasibility of novel technology fusing echocardiography and fluoroscopy images during Mitraclip interventions. Eurointervention. 2014;9:1210-6.

25. Krishnaswamy A, Kapadia S, Tuzcu M. Percutaneous paravalvular leak closure. Imaging, techniques and outcomes. Circulation J. 2013;77:19-27.

26. Kempfert J, Noettling A, John M, Rastan A, Mohr FW, Walther T. Automatically segmented DynaCT: enhanced imaging during transcatheter aortic valve implantation. J Am Coll Cardiol. 2011;58:e211.

27. Balzer J, Hall S, Rassaf T, Boring Y, Franke A, Lang R, et al. Feasibility, safety and efficacy of real-time three dimensional transoesophageal echocardiography for guiding device closure of interatrial communications: Initial clinical experience and impact on radiation exposure. Eur J Echocardiography. 2010;11:1-8.

28. Jone $P$, Ross $M$, Bracken J, Mulvahill M, Di Maria M, Fagan T. Feasibility and safety of using a fused echocardiography/fluoroscopy imaging system in patients with congenital heart disease. JASE. 2016;29:513-21. 